\title{
Low vision rehabilitation over the course of a year: The experiences and feelings of elderly people with visual impairments
}

\author{
Heidi J. Siira*1,2, Aura A.K. Falck ${ }^{2}$, Helvi A. Kyngäs ${ }^{1}$ \\ ${ }^{1}$ Research Unit of Nursing Science and Health Management, University of Oulu, Oulu, Finland \\ ${ }^{2}$ Department of Ophthalmology, Medical Research Center and PEDEGO Research Unit, University of Oulu and Oulu University \\ Hospital, Finland
}

Received: February 20, 2019

DOI: $10.5430 /$ jnep.v9n8p16
Accepted: April 3, 2019

Online Published: April 18, 2019

\begin{abstract}
Background/Objective: Low vision rehabilitation (LVR) services aim to help people of all ages with visual impairment (VI) to maintain and improve their quality of life and well-being. However, knowledge about elderly people's subjective experiences of the usefulness as well as their expectations of LVR is very limited. The aim of this study was therefore to produce new knowledge that can be utilized in the development and improvement of LVR processes and services in order to better support well-being and quality of life, and encourage the 'active aging' of elderly people with VI.

Methods: Qualitative research methods were used. The data was collected from elderly people with VI $(\mathrm{n}=35)$ by unstructured telephone interviews one year after the onset of individual LVR. The data was analyzed by inductive content analysis.

Results: Numerous and varied expectations were expressed for LVR, showing mainly hopes for vision improvement and the need for services and support. The impact of medical care on vision outcome was mentioned in relation to the perceived benefits of LVR. LVR was generally considered useful in terms of overall well-being and quality of life, the main practical benefits being the provision of different visual aids and assistive devices.

Conclusions: The results proved the concept, process and multi-sided nature of LVR to be incompletely perceived by the participants in the study. In light of this, we argue that there is a need for improved communication between people with VI and medical staff when discussing the nature and the realistic possibilities of LVR; care should be taken to distinguish it from medical care. The benefits of LVR in enabling independence in daily tasks were commonly recognized, however.
\end{abstract}

Key Words: Visually impaired, Elderly people, Low vision rehabilitation

\section{INTRODUCTION}

A vivid metaphor of the "silver tsunami" has been used to describe the rapid and worldwide phenomena of population aging in the 21 st century. ${ }^{[1]}$ In $2017,13 \%$ of the global population was estimated to be aged 60 or over, and in Europe the figure was $25 \% .^{[2]}$ Currently in Finland, $21 \%$ of the popula- tion is aged 65 years or over and national projections show that the number of elderly people will have increased by the year 2060 to an estimated $29 \%$ of the population. ${ }^{[3]}$ The oldest of the old (people aged 80 and over) present the greatest challenge in terms of providing health-related services and finding ways to help them to maintain independence in their

\footnotetext{
*Correspondence: Heidi J. Siira; Email: heidi.siira@ oulu.fi; Address: Research Unit of Nursing Science and Health Management, University of Oulu, Oulu, Finland.
} 
everyday life. ${ }^{[4]}$ The global burden of disease is expected to increase in line with the aging population, and is predicted to be heaviest among disorders that are strongly associated with advancing age. ${ }^{[5]}$ Impaired vision is a common condition affecting older members of the population, together with declining movement, hearing and cognition. Age of onset, support and services available, as well as individual coping strategies determine what kind of impact vision loss or deterioration has on the lives of the elderly. ${ }^{[4]}$

In Finland, LVR services are provided to people who meet the criteria of VI set by the World Health Organization (WHO), according to which a person is visually impaired if the visual acuity (VA) in the better eye with the best glass correction is less than 0.3. A person is considered blind if the VA of the better eye is less than 0.05 or the radius of the visual field is less than 10 degrees. $^{[6]}$ According to FinTerveys 2017 data, approximately 50000 people (1\% of the Finnish population) are estimated to be visually impaired. ${ }^{[7]}$ In Finland, VI particularly affects the aging segment of the population. ${ }^{[8]}$ The vast majority $(80 \%-85 \%)$ of the newly registered persons in the national register of VI are people aged 65 years or over. The most common eye disease causing long-term VI in Finland, and also across Europe, is age-related macular degeneration. ${ }^{[8,9]}$ In addition, there is a large number $(173,000)$ of mostly elderly people in Finland with visual problems not quite meeting the VI criteria, having a moderate longdistance VA ( 0.5 to 0.32 Snellen decimal) but experiencing such weak functional vision that they need help, services and counseling in order to survive in their everyday life. ${ }^{[8]}$

Loss of vision is a physical disability which has a profound psychological dimension, one that seriously affects people's sense of well-being. ${ }^{[10,11]}$ Therefore, a fully supportive home environment for the elderly should not only promote social and physical well-being, but also psychological wellbeing. ${ }^{[12]}$ VI also seriously compromises quality of life and has been linked to a weakened financial situation, declining physical and mental health and functional constraints that affect everyday life and self-reliance, causing social isolation and low life satisfaction. ${ }^{[13,14]}$

Modern LVR can be defined as a multidisciplinary professional service that aims at optimal use of residual visual functions, training in compensative skills and reintegration in society. ${ }^{[15]}$ LVR not only includes professionals working in the fields of ophthalmology and optometry but also occupational therapy, social work and various teaching disciplines. ${ }^{[15]}$ Despite this wide-ranging professional involvement in the field, there is currently little research on VI and LVR available. Previous international research on LVR has focused on people of retirement age, but information and

Published by Sciedu Press knowledge on how LVR can help maintain and improve the perceived quality of life and well-being of older adults with VI is still limited. ${ }^{[16]}$ Earlier studies on LVR have shown that assistive devices improve functional vision under test conditions, but as yet no effect has been demonstrated in the home environment. ${ }^{[16]}$ Also, there is little research on the cost effectiveness of LVR. Group-based LVR interventions ${ }^{[16]}$ as well as interdisciplinary low vision services ${ }^{[17]}$ have had encouraging results and a positive impact on the lives of service users. ${ }^{[17]}$ It is clear then, that more research is needed on home-based LVR services, counseling and guidance, as well as the efficacy of assistive devices and equipment. In addition, there is also limited information about the experiences of elderly people with LVR, and the expectations they have for LVR. The need to solicit user perspectives of LVR services and attempt to achieve a good fit between client needs and services provided. ${ }^{[18]}$ Future research needs base on knowledge of elderly people readjusting to everyday life after a recent diagnosis of vision loss, and call for implementation of knowledge in rehabilitation programs at municipality level at the early stages of vision loss. ${ }^{[19]}$

In the light of the previous patchy research concerning LVR and the gaps in our knowledge that remain, this study is important for Western societies as a whole; there is a definite urgency for us to consider ways to improve the functional capacity of aging populations and to mitigate as far as possible the negative effects of aging. Policy objectives and the preferences of elderly people to "age in place" coincide in that they refer to people being able to stay at home and in a familiar neighborhood by adapting to changing needs and conditions that occur as people age. ${ }^{[20]}$ This study enriches the scarce field of disability research by introducing a nursing science perspective, and supplements the general image of VI among elderly people by bringing out their own voices directly. The study provides a basis for assessing the usefulness of LVR, and the results outline possibilities for future research approaches. The ultimate purpose of this study is to explore the experiences of elderly people with VI in LVR after a period of one year, expectations for LVR in the future, and the usefulness of LVR in terms of improving well-being and quality of life. We seek to produce new knowledge that can be utilized in the development and improvement of LVR processes in order to better support well-being, improve the quality of life and encourage active aging in place of elderly people with VI as much as possible.

Research questions were: 1) How do VI elderly people assess their experiences of the LVR process after a period of one year? 2) What are the expectations of VI elderly people for LVR in the future? 3) What things do VI elderly people consider beneficial and useful in LVR for their well-being 
and quality of life?

\section{Methods}

\subsection{Study protocol}

The study is part of a larger, mainly quantitative followup study that examines the health-related quality of life (HRQoL) and well-being of home-dwelling elderly people with VI in relation to their home environment, the severity and degree of VI and the LVR process. Qualitative data was collected to study people's experiences, their expectations and the tangible benefits of LVR. The setting was the
Northern Ostrobothnia Hospital District in northern Finland and Oulu University Hospital Low Vision Center (OLVC), which receives all patients referred to LVR in the Hospital District area in question. A prospective cohort of consecutive older adults with VI referred to OLVC for LVR was included. Recruitment took place in OLVC during a 12-month period from May 2016 to May 2017. People eligible for inclusion were aged 65 years or over, living at home and visually impaired according to the WHO definition. ${ }^{[6]}$ There were 79 referrals, and 39 persons ended up taking part in the study. Flowchart of the study protocol can be seen in Figure 1.

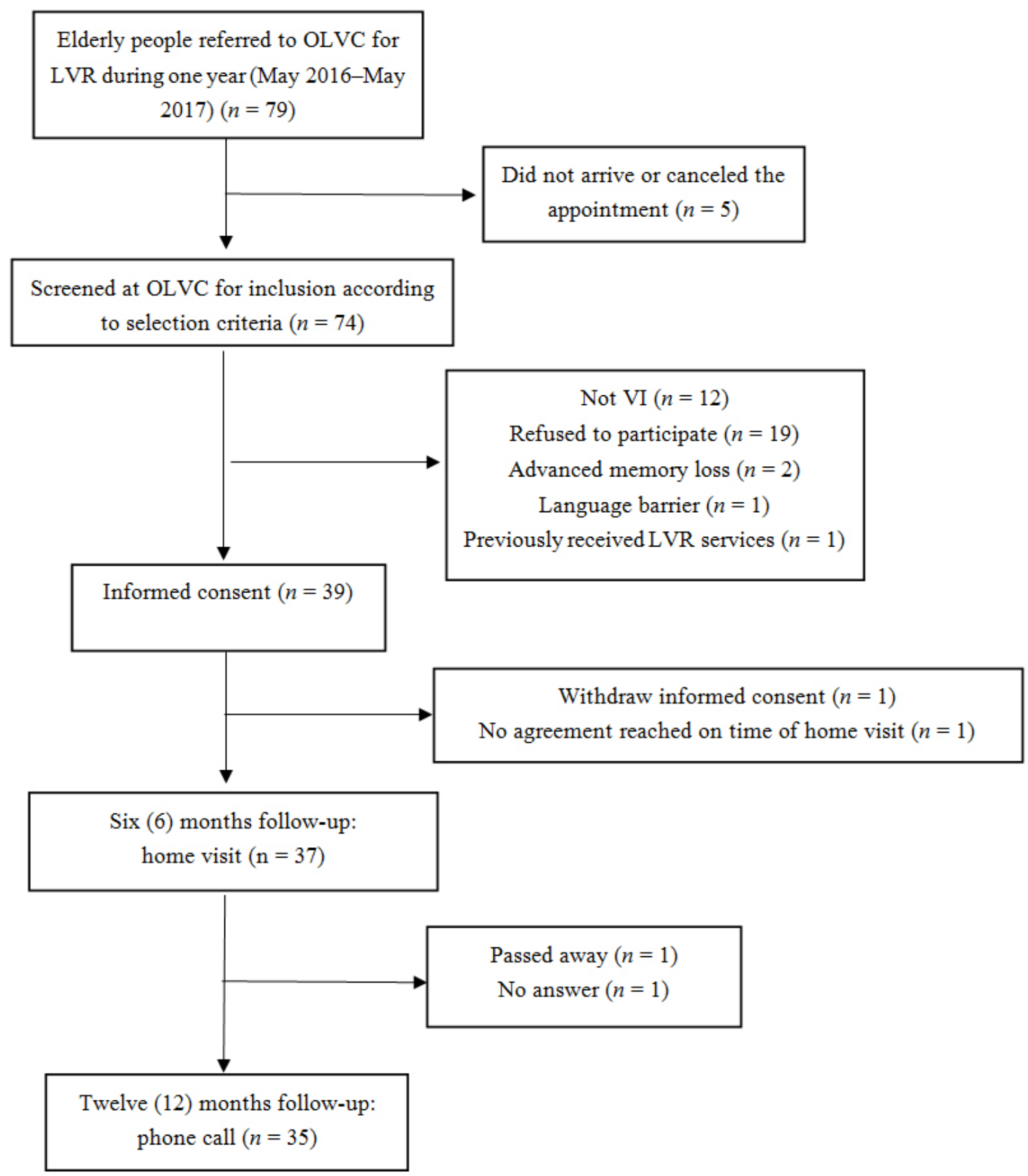

Figure 1. Flowchart of the study protocol 


\subsection{Data collection}

The research data were collected by telephone interviews at the point when individual LVR had lasted for one year. The researcher had visited each participant at home six months previously. 35 of the 39 were available for the phone interview. If the participant was busy or otherwise unable to answer the questions at the time of the phone call, a new time was scheduled within a few days. One of the interviews was split into two sessions. Nobody refused to be interviewed after answering the phone.

A telephone interview was selected as a data collection method because answering questions on the phone is easy for the participants and does not require much effort on their part (such as traveling somewhere or writing answers to a questionnaire). Telephone interviewing is considered to be a participant-centered data collection method, ${ }^{[21]}$ and suits cases where contact with participants has already been made. ${ }^{[22]}$ Conducting a telephone interview was also a costeffective way to collect data in northern Finland, where long geographical distances present very practical difficulties for fieldworkers.

The elderly participants were oriented by telling them that the questions would deal with LVR, an explicit reference to a process that had begun a year ago when they first visited OLVC as referral patients. LVR includes individually planned actions which assess the customer's overall situation, planning and monitoring the rehabilitation process, service management, disability-related support, counseling and guidance, adaptation training, evaluation and guidance related to home-environment as well as providing and fitting the visual aids and other assistive devices.

Three open questions were asked: 1) How have you experienced the LVR process during the past year? 2) What kind of expectations do you have for LVR in the future? 3) What has been useful in the LVR from your well-being and quality of life point of view, and why? Telephone interviews lasted 15-75 minutes. The researcher wrote the answers down manually on a sheet of paper during the telephone conversation. Communication on the phone was successful and uncomplicated, although many respondents were using a hearing aid. Age and gender as background variables were registered. Diagnoses of primary eye disease and level of VI were collected from patient records. The answers were compiled for analysis with word-processing software (Microsoft Word), and the participants were encoded by numbers in order to anonymize the data. The raw data consisted of seven pages of written text of 11-point font, single-spaced. The data appeared on first reading to be rich but fragmented.

\subsection{Data analysis}

The data was analyzed by inductive content analysis, following Elo and Kyngäs. ${ }^{[23]}$ The main phases of analysis were preparation, organizing and reporting. Initially, the material was read through several times to form an overall view and get a general sense of the data, while making notes to the material to organize it. The unit of analysis was selected to be an expression of a theme. The analysis was focused on the manifested content of the data. Original expressions corresponding to the research questions were identified, listed and simplified, and then grouped by combining expressions that seemed to be one or mean the same, in order to form subcategories. Abstraction of the data was continued by forming common descriptive upper categories of sub-categories. Upper categories were named after their content.

\subsection{Ethics}

The study has been approved by the Northern Ostrobothnia Hospital District and the Regional Ethics Committee. The study follows good scientific practice and research ethics principles according to the Finnish Advisory Board on Research Integrity 2012, and adheres to the guidelines of the 2017 Helsinki Declaration of the World Medical Association. ${ }^{[24,25]}$ The participants in the study have given voluntary informed consent to participate in the research at the outset of LVR and first visit to OLVC.

\section{Results}

\subsection{Characteristics of participants}

Mean age of the participants at the time of the interview was 84 years (range 71-94). A majority of the participants were women $(n=25)$. Eye disease mainly responsible for VI was age-related macular degeneration or other retinal disease ( $n=31)$, followed by glaucoma $(n=4)$. The participants were divided into categories describing the severity of VI according to WHO classification ${ }^{[6]}$ as follows: moderate VI (1) $(n=30)$; severe (2) VI ( $n=4)$; and deep (3) VI ( $=1)$.

\subsection{Experience of a one-year low vision rehabilitation process}

Four upper categories described experiences of LVR after one year: satisfaction/dissatisfaction with services; suitability and functionality of visual aids; medical treatment of eye disease; and psychological factors. The upper category of LVR as medical treatment emphasized the impact of medical care or surgical procedures on vision outcomes. Regular or repeated treatment at the time of the interview due to eye disease was discussed, most commonly the injection treatment of wet age-related macular degeneration. The decision to withdraw from medical treatment due to it not having a 
significant or a desired impact on visual acuity was considered, as were the medical possibilities available to treat the eye disease.

"One cannot say that there have been significant benefits from low vision rehabilitation or visual aids because the vision itself cannot be cured." (ID 8, Female)

"My low vision rehabilitation was discontinued. It was said that it can no longer be cured. Earlier, I was receiving injections." (ID 39, Male)

"It [vision] is by no means rehabilitated. There are no therapies available.” (ID 27, Female)

The upper category of satisfaction/dissatisfaction with services raised notions of their adequacy and accessibility, as well as their usefulness for everyday life. The fact that LVR services have been brought home in the form of visual aids and improvements for lighting was considered good. Likewise, the services were considered easily accessible as use of the Internet was not necessary. Certain unmet needs were identified concerning the visual aids, services and contact with the rehabilitation counselor. Some uncertainty was expressed about whether LVR had taken place at all. Discussion support provided by different occupational groups at various stages of the LVR process was also hoped for.

"Help, I have received, yes. OLVC has provided visual aids at home, and lights have been improved for disability. Online access has not been needed for rehabilitation services." (ID 17, Female)

"Not in any way; I do not experience having low vision rehabilitation on my part." (ID 7, Female)

"Absolutely non-existent. Just one contact had." (ID 15, Female)

"Quite bad. I have hardly gotten [any] visual aids. There has not been a home visit by the rehabilitation counselor; they called once, but the time was not suitable for me, and a new time for the visit has not been offered." (ID 4, Female)

"There has not been a proper discussion. I was disappointed at not having been able to talk to a doctor, really not once. The bright lights were installed, but no question was ever asked. I've missed discussions." (ID 28, Female)

The suitability, functionality, usability and usefulness of visual aids in supporting independent living were considered. On one hand, the visual aids were found to be functional, useful and easy to use, but on the other hand, they were found difficult to use, not very helpful or laborious. In addition, uncertainty about the skills required to use the visual aids properly was expressed.

"I got the magnifying glasses so I can read the things I want." (ID 12, Female)

"There is one magnifying glass, but I cannot use it. I do not know if it is helpful and I'm not even sure if I can use it correctly and appropriately." (ID 15, Female)

The year-long LVR process also inspired reflections on the profound feelings and emotions of becoming disabled and adapting to visual impairment. The deterioration of vision aroused feelings of depression which, sadly, seemed inevitable. Treatment visits - many participants were receiving anti-VEGF injections for AMD on a regular basis - in the hospital were also found to be exhausting. The importance of the participants' own attitudes, motivation, activity and passivity, and the impact of their own approving or negative attitude on the success of the overall LVR process was also reflected on. It was commonly felt that one has to survive in everyday life on one's own; there is much that simply cannot be done by an outsider. A certain level of contentment with the situation despite advanced age was exhibited, but the visual aid provided could be unpleasant and there was some reluctance to learn how to use it. Visual aids had sometimes been consistently refused although they had been repeatedly offered. Nevertheless, activity in the use of visual aids was also demonstrated.

"It depresses me that my sight has gone". (ID 4, Female)

"Every morning, when I open my eyes, it's dark." (ID 11, Female)

"I said then that I do not want [visual aids]. They were offered on several occasions, I abandoned those as I was thinking 'I'm not blind yet'." (ID 19, Male)

"I have not learned to like the electronic video magnifier much, and I have not had a desire to learn because I am not succeeding." (ID 8, Female)

\subsection{Expectations for low vision rehabilitation}

Four upper categories were found to describe expectations for future LVR. These related to vision quality, gaining information, the level of services and support, as well as the roles of the patient and the doctor. Some participants expressed a cautious sense of contentment with the current state of their vision, and hoped that their vision would not deteriorate 
or that eye disease would not lead to complete blindness. However, the knowledge that in some circumstances nothing can be done or that there is no healing treatment available showed a degree of realism about declining visual ability. Yet set against this sober realism, there was also a longing for an improvement in visual acuity, finding a cure, and getting a driving license back.

"That sight would not go completely. That I would maintain some kind of vision." (ID 4, Female)

"... to get better vision, for example through surgery, to survive better in everyday life." (ID 11, Female)

"I hope to have my driving license back, if only I could see one line better." (ID 10, Male)

The expectations related to gaining practical information were characterized by uncertainty of whether something could be done to improve vision, and unawareness about the support and services available. The expectations for LVR were also not considered or not known about.

"I cannot say if there is anything, because it was said that glasses would not help." (ID 9, Female)

"What kind of glasses and aids would I get? There are some, but I do not know where to get them." (ID 14, Female)

There were various expectations of services and support: contact by the rehabilitation counselor and an out-patient visit to the doctor was hoped for, as well as the provision of visual aids and financial assistance. Recreational activities, such as camps, were desirable for day-out breaks. The importance of timing and the continuity of LVR were also emphasized.

"Visiting the OLVC was too early, I was not ready to gain and comprehend information." (ID 28, Female)

"I hope that rehabilitation will continue for as long as possible." (ID 25, Male)

Expectations brought up for LVR also related to the roles of the doctor and the patient. The role of the patient was essentially seen as one of passive outsider in the treatment, while responsibility and authority for the treatment and situation was given to the doctor. Adaptation to VI was reflected through the fears raised of blindness, thoughts of death and pondering survival in everyday life as vision deteriorates. However, not having expectations for LVR reflected adaptation to the current situation and the services received, and knowing where to turn to with needs related to LVR.

Published by Sciedu Press
"I cannot answer, it's for the doctors." (ID 16, Male)

"What I have thought about, is that how do I manage when I cannot see, whether I should set threads around the room, different colors don't even help, when you cannot see them. One must start to recognize based on the sound." (ID 37, Male)

"It's not too long ago when the rehabilitation counselor left a phone number that I could call. Things do not come to mind right now." (ID 31, Female)

\subsection{The usefulness of low vision rehabilitation in terms of well-being and quality of life}

Seven upper categories were found to describe the usefulness of LVR: visual aids that enable seeing, coping in the home environment, independent living in everyday life, thoroughness and accessibility of LVR services, patient involvement in the LVR process, negative feelings and thoughts, and comprehending LVR as medical treatment of the eyes. The main benefits of LVR for well-being and quality of life stemmed from the different devices provided that aid vision (electric video magnifiers, magnifying glasses and binoculars). However, the use of these assistive devices was perceived as somewhat awkward - they provided just a little bit of help or no help at all. The electric video magnifier was liked, almost without exception, however.

"Magnifiers - with them I can see something. I'll check the mail with the help of them." (ID 24, Female)

"With an electric video magnifier, I look at magazines and bills. It is the most useful tool, it is good." (ID 22, Male)

Practical modifications to the living environment, such as making lighting improvements, were also held to be a beneficial result of LVR. Assistance with maintaining the familiar order of things in the home, and improving ways of gaining information and carrying on communication with others were also appreciated. This could involve very simple innovations: for example, notes and instructions were made more legible by using a black marker instead of an ordinary pen.

"The [new] lights have definitely been a good thing. I did not think (they would be available), and I did not think to ask for them." (ID 29, Female)

"The familiar environment and things in their own places help to find and survive." (ID 11, Female) 
In an example of hearing compensating to some extent for sight loss, audiobooks and voice subtitling services were used for leisure reading and to acquire practical information. Sensory-based means were also used to facilitate practical housekeeping tasks, e.g. marking the stove and other household appliances. In addition, the availability of family members for reading aloud and providing help was taken advantage of. The services of OLVC and LVR in general are thought to be thorough and accessible, and to have eased the life of the respondents in various ways; having it explained why, for example, vision has deteriorated was appreciated. The fact that it was possible to bring things home was considered as a particularly good aspect of the services.

"Thoroughly cared for and studied. Eased feeling." (ID 27, Female)

"I know now what is wrong." (ID 31, Female)

The usefulness of LVR was considered by looking at the importance of involving patients in the LVR process. Experiencing oneself as an active actor contributes to independent survival in the service system. The responsibility of the individual was emphasized in cases where an elderly person with VI had at first refused the LVR services and visual aids offered, but later on realized that they would, in fact, be of use. However, sometimes the assistive devices and aids were not actively used in everyday life, or their usability was not maintained by replacing the batteries, regular servicing, etc.

"I can still handle things." (ID 27, Female)

"I have not used much [aids]. I have not always had the magnifying glass with me while shopping. And if the battery runs out, I will not always realize to buy a new one." (ID 26, Female)

LVR and VI also raised negative thoughts and emotions. In some cases LVR was perceived as useless because wishes and expectations were not fulfilled. More particularly, the usefulness of LVR was evaluated solely in relation to vision and positive changes, and because it did not restore vision LVR was dismissed out of hand.

"I do not feel anything useful. I feel it's difficult that I have become disabled in later life. It irritates me." (ID 7, Female)

"It has not been any good because my vision has not improved." (ID 37, Male)

\section{Discussion}

In this paper LVR was studied through the subjective experiences, the expectations and benefits perceived by a group of elderly people with VI in order to better understand a point of view that has hitherto been largely ignored by researchers and practitioners. The experiences of LVR after it had lasted for one year manifested as satisfaction and/or dissatisfaction with services, the use or non-use of suitable and functional visual aids, ophthalmological treatments and in various psychological forms. Based on the results, the concept, process and multisided nature of LVR proved to be problematic. The conclusion must be that the realistic possibilities and actions of LVR should be more clearly communicated to elderly patients right from the beginning of the LVR process. The differences between LVR and medical treatment should also be clearly stated and clarified if necessary. In reaching this conclusion we follow previous studies ${ }^{[18,26]}$ which also called for improved communication between LVR customers and providers.

The participants in the study had some trouble defining their expectations for future LVR. Elderly might express only a few demands for support if they are told by a doctor that their vision could not be improved. ${ }^{[19]}$ Practical help with assistive devices and technology makes for an exception, ${ }^{[19]}$ which was also seen in this material. Expectations related to LVR showed clear hopes for positive rehabilitation outcomes, such as major improvement in eye health status, and for it to answer the need for information concerning services and support. The hope for sufficient improvement in vision in order to get a driving license back is unrealistic from the point of view of medical care but understandable in the light of the review noting that individuals with VI find that driving is something which is particularly difficult to relinquish. ${ }^{[27]}$ After all, car ownership and driving symbolizes freedom and highly valued independence. The hope that vision will no longer deteriorate or eye disease will not lead to complete blindness so that survival in everyday life will not get any more difficult was also expressed by many. Again, we may relate our findings to those of Magnus and Vik, ${ }^{[19]}$ who studied elderly people recently diagnosed with age-related macular degeneration and found similar perceptions of fear of more extensive vision loss that would threaten independence and reduce activity in everyday life.

LVR was generally considered useful in terms of overall well-being and quality of life. The benefits were mainly practical - the provision of visual aids and assistive devices, assisted survival in the home environment and improved, independent coping with the challenges brought by VI in everyday life. Lighting adaptation was seen as a particularly important part of LVR. Previous research supports this confident assertion by noting that better lighting significantly improves the quality of life of elderly people with VI, and that good lighting contributes to the ability to carry out daily 
activities. ${ }^{[28]}$ Reading is vital in everyday life activities both at home and in its surroundings, ${ }^{[19]}$ and the ability to read with the help of optical aids was seen as important. The participants who were using an electronic magnifying reader considered it as a particularly good visual aid. Electronic magnification provides superior magnification compared to normal handheld devices and is one of the most advanced interventions in LVR technology available today. ${ }^{[15]}$

Information and communication technology (ICT) devices and applications such as computers, laptops, smartphones and tablets were not mentioned by our participants as being extensively used as visual aids. Yet mobile phones in particular have been widely considered as promising in terms of improving quality of life for the elderly. ${ }^{[29]}$ At bottom, this may well be a generational issue as people from the younger generation who have poor vision or suffer from blindness currently take full advantage of digitalization, and it is likely that future generations will want to keep using digital solutions into old age, despite impaired vision, if they have become familiar with the devices and applications earlier in life. ${ }^{[29]}$ Somewhat related to this is the fact that the subjects of this study made it clear that they were very pleased to be able to contact the LVR services without having to use the Internet. However, Internet access may well be considered a minor issue after a decade or two.

It is noteworthy that training was not brought up in terms of its importance in adapting to vision loss, VI and coping in everyday life - not even when learning the use of visual of aids and the skills of the visually impaired proved to be challenging in some degree. The need for discussions with professionals during the first year of LVR is clear from our results. In developing the LVR process, it would be worth considering whether elderly people with VI would benefit from a group-based intervention on adaptation training rather than individual guidance; indeed, counseling sessions as group-based LVR interventions have already produced encouraging results. ${ }^{[16]}$ A control phone call for a period might also be beneficial in helping to maintain the LVR relationship with elderly people and assisting them to adapt to their new situation and comprehend the range and possibilities of support available for everyday life. Scheduled control calls require resources, of course, but investing in adaptation training can save healthcare costs in the future, as elderly people with VI stay active and independent actors in their lives for longer despite suffering from VI. In some cases, the first visit to OLCV and the onset of LVR was too soon after the diagnosis. Resources should be concentrated on assisting those who need to understand the nature and difficulties of life for an elderly VI person; as Ivanoff et al. suggest, ${ }^{\text {[30] }}$ early detection and better integration within the system of

Published by Sciedu Press people with VI might improve the effectiveness of LVR.

In the future, our understanding of the experiences and perceptions of elderly people with VI of LVR should be further deepened with qualitative research methods, and findings should be compared to the LVR services provided by gathering information from patients' records. Aspects of missed care in relation to LVR should also be considered in future research as the feeling of non-existent or inadequate LVR was evident in this study. In the development of the LVR process the use of outcome indicators and measures, such as quality of life instruments, should be used to support individual goal setting and assessing the effectiveness of LVR. Outcome measures would also help the patients to perceive and comprehend the contents and possibilities of LVR, which would increase commitment to LVR and empower elderly patients with VI in the rehabilitation process.

The trustworthiness of the study is discussed by looking at issues of credibility, transferability, dependability, confirmability and authenticity. ${ }^{[31]}$ Inductive content analysis is well suited to the analysis of this data, as it is a data-driven and material-sensitive method for analyzing qualitative information. ${ }^{[23]}$ Extensive dialogue among co-researchers was used to increase the dependability of the analysis. It should be emphasized that the researcher has a great deal of experience working with elderly people so she was able to discuss sensitively the issues involved with aging, VI and home survival with the participants of the study. The researcher has also been working as a rehabilitation counselor with other elderly patients, so she had a preliminary understanding about LVR and some of the general perceptions elderly people had about it. However, the researcher was thoroughly professional and did not let her pre-understanding influence the research in any way, although it did help her to understand and empathize with the elderly participants during the interviews. The conclusions made are based purely on the research data. The transparency, consistency and confirmability of the analysis process can be seen in Figure 2.

The respondents were familiar with the researcher from previous points of longitudinal follow-up data collection. The researcher was therefore a familiar person that facilitated the interviews. The participants were selected from a prospective sample at the beginning of the follow-up study according to certain inclusion criteria, and with their particular age and gender distribution, they are an accurate sample of the Finnish population of VI people. They all had the same possibilities to receive LVR services, get counseling, adaptation training, visual aids and other services because of national health insurance. The participants are therefore a very het- 
erogeneous group of people with their disabilities, place of visual status, the majority being moderately VI because of residence and their state of overall health. On the other hand, age-related macular degeneration. the subjects are also homogeneous when it comes to their

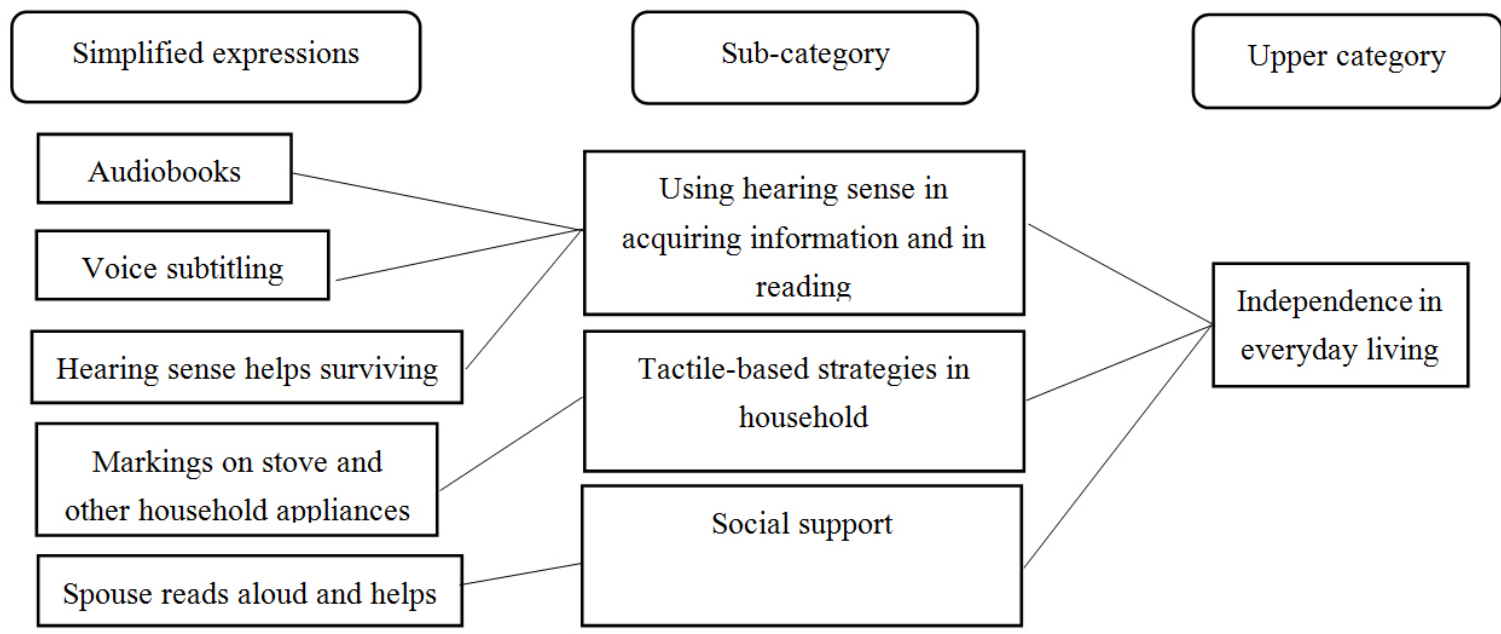

Figure 2. Independence in everyday living as a useful outcome of LVR in terms of well-being and quality of life

Not recording the telephone calls is a factor that may decrease the reliability of research. However, the researcher wrote the answers down as accurately as possible and checked with the respondents whether the expressions written down were what the respondents had meant. The respondents were asked, based on the pre-understanding of the researcher, what aspects of LVR are useful in terms of their well-being and quality of life. Not all the respondents understood the question, and they had to be given examples of things that might be useful, for example visual aids. A pilot interview might have brought up the fact that LVR as a concept was not completely familiar to all of the respondents. It was explained to all of the participants at the beginning of the interviews how LVR is understood in this study; it was also explained that for the purposes of the study they had to consider that the process of LVR had begun at their first visit to OLVC one year before. The study produced a multi-sided and information saturated rich seam of data that allowed us to produce relevant and consistent conclusions. The illustrative quotations were chosen based on the perceptions of the first author who saw them as relevant to the research questions. The research results are transferable to other hospital districts in Finland because the data is nationally representative. ${ }^{[8]}$ The results can also be utilized internationally in similar LVR contexts concerning elderly people. The inclusion criteria of

\section{REFERENCES}

[1] Nikolich-Žugich J, Goldman DP, Cohen PR, et al. Preparing for an aging world: engaging biogerontologists, geriatricians, and the the research also support transferability.

\section{Conclusion}

During their year of low vision rehabilitation others adapted to VI by learning the use of assistive devices and adopting appropriate substitutive behaviors to cope with a decline in their VA in everyday life. In contrast, others demanded a significant - almost certainly unrealistic - improvement in vision, set great expectations for medical care and were reluctant to learn new compensative skills such as correctly using visual aids. Frankly discussing the nature and the realistic possibilities of LVR with the patients, especially distinguishing it from medical care, apparently needs emphasizing. In general, the overall experience of the participants in this study is that LVR does improve the well-being and quality of life as well as independent and active aging in place despite VI, but, paradoxically, stimulating such an active and realistic attitude can create the conditions for failure in some cases.

\section{ACKNOWLEDGEMENTS}

The authors express their deep gratitude to the participants who took part in the study.

\section{CONFlicts OF INTEREST Disclosure}

The authors declare that there is no conflict of interest. society. J Gerontolol A Biol Sci Med Sci. 2016; 71(4): 435-444. PMid:26419976 https ://doi . org/10.1093/gerona/glv164

[2] United Nations. Department of economics and social affairs. Popula- 
tion Division. World population prospects. The 2017 revision. Key findings and advance tables. New York. 2017. [cited 2019 Jan 3]. Available from: https://esa.un.org/unpd/wpp/publicatio ns/files/wpp2017_keyfindings.pdf

[3] Statistics Finland 2017. [cited 2018 Oct 30]. Available from: https://www.stat.fi/tup/julkaisut/tiedostot/julkai suluettelo/yyti_sul_201700_2017_17860_net.pdf

[4] Mann WC. The aging population and its needs. IEEE Pervasive Comput. 2004; 3(2): 12-14. https://doi.org/10.1109/MPRV. 2004. 1316812

[5] Prince MJ, Wu F, Guo Y, et al. The burden of disease in older people and implications for health policy and practice. Lancet. 2015; 385: 549-562. https://doi.org/10.1016/S0140-6736(14) 6 1347-7

[6] World Health Organization (WHO). Prevention of blindness \& deafness. Consultation on development of standards for characterization of vision loss and visual. 2003. Geneva. [cited 2019 Jan 4]. Available from: http://apps.who.int/iris/bitstream/handle/106 65/68601/WHO_PBL_03.91.pdf? sequence $=1 \&$ is $\mathrm{s} A$ llowed=y

[7] Koponen P, Borodulin K, Lundqvist A, et al. Terveys, toimintakyky ja hyvinvointi Suomessa - FinTerveys 2017-tutkimus. Terveyden ja hyvinvoinnin laitos (THL), Raportti 4/2018. Available from: http://www.julkari.fi/bitstream/handle/10024/1362 23/Rap_4_2018_FinTerveys_verkko.pdf?sequence=1\&isA llowed=y

[8] Ojamo M. Annual statistics 2017. The Finnish Register of Visual Impairment. National Institute for Health and Welfare (THL). Available from: https://www.nkl.fi/index.php?__file_display_id $=12663$

[9] Mitchell P, Liew G, Gopinath B, et al. Age-related macular degeneration. Lancet. 2018 Sep; 392 (29): 1147-1159. https ://doi.org/ 10.1016/S0140-6736 (18) 31550-2

[10] Harada S, Nishiwaki Y, Michikawa T, et al. Gender difference in the relationship between vision and hearing impairments and negative well-being. Prev Med. 2008; 47: 433-437. PMid:18619483 https://doi.org/10.1016/j.ypmed .2008.06.011

[11] Pinquart M, Pferffer JP. Psychological well-being in visually impaired and unimpaired individuals. A meta-analysis. The $\mathrm{Br} \mathrm{J}$ Vis Impair. 2011; 29(1): 27-45. https://doi .org/10.1177\%2F0264 619610389572

[12] Elo S, Saarnio R, Isola A. The physical, social and symbolic environment supporting the well-being of home-dwelling elderly people. Int J of Circumpolar Health. 2011; 70(1): 90-100. https: //doi.org/10.3402/ijch.v70i1.17794

[13] Brown RL, Barrett AE. Visual impairment and quality of life among older adults: an examination of explanations for the relationship. The Journals of Gerontology, Series B: Psychological Sciences and Social Sciences. 2011; 66: 364-373. https://doi.org/10.1093/gero $\mathrm{nb} / \mathrm{gbr} 015$

[14] La Grow SJ, Towers A, Yeung P, et al. The relationship between loneliness and perceived quality of life among older persons with visual impairments. J Vis Impair Blind. 2015; 487-499. https: //doi.org/10.1177\%2F0145482X1510900606

[15] Markowitz SN. State-of-the-art: low vision rehabilitation. Can J Ophthalmol. 2016 April; 51(2): 59-66. https://doi.org/10.1016/ j.jcjo.2015.11.002

[16] Binns AM, Bunce C, Dickinson C, et al. How effective is low vision service provision? A systematic review. Surv Ophthalmol. 2012;
57: 34-65. PMid:22018676 https://doi.org/10.1016/j . surv ophthal.2011.06.006

[17] Hinds A, Sinclair A, Park J, et al. Impact of an interdisciplinary low vision service on the quality of life of low vision patients. Br J Ophthalmol. 2003; 87: 1391-1396. https://doi.org/10.1136/ bjo.87.11.1391

[18] Southall K, Wittich W. Barriers to low vision rehabilitation: a qualitative approach. J Vis Impair Blind. 2012 May; 261-274. https: //doi.org/10.1177/0145482X1210600502

[19] Magnus E, Vik K. Older adults recently diagnosed with age-related vision loss: readjusting to everyday life. Act Adapt Aging. 2016; 40: 296-319. https://doi.org/10.1080/01924788.2016.12 31460

[20] Weil J, Smith E. Revaluating aging in place: from traditional definitions to the continuum of care. Working with older people. 2016; 20(4): 223-230. https://doi.org/10.1108/WWOP-08-2016-0 020

[21] Trier-Bieniek A. Framing the telephone interview as a participantcentred tool for qualitative research: a methodological discussion. Qual Res. 2012; 12(6): 630-644. https://doi.org/10.1177\%2F 1468794112439005

[22] Carr ECJ, Worth A. The use of the telephone interview for research. Journal of Research in Nursing. 2001; 6(1): 511-524. https : //doi.org/10.1177\%2F136140960100600107

[23] Elo S, Kyngäs H. The qualitative content analysis process. J Adv Nurs. 2008; 62(1): 107-115. PMid:18352969 https://doi.org/ $10.1111 / j .1365-2648.2007 .04569 . x$

[24] Finnish Advisory Board on Research Integrity (TENK). 2012. [Internet] [cited 2019 Jan 3] Available from: http://www.tenk.fi/en

[25] World Medical Association (WMA) [Internet]. Declaration of Helsinki - Ethical Principles for Medical Research Involving Human Subjects. 2017. [cited 2019 Jan 4] Available from: http://www . wma.net/policies-post/wma-declaration-o f-helsinki-ethical-principles-for-medical-researc h-involving-human-subject

[26] Lam N, Leat SJ. Barriers to accessing low-vision care: the patient's perspective. Can J Ophthalmol. 2013 Dec; 48(6): 458-462. https://doi.org/10.1016/j.jcjo.2013.02.014

[27] Nyman SR, Dibb B, Victor CR, et al. Emotional well-being and adjustment to vision loss in later life: a meta-synthesis of qualitative studies. Disabil Rehabil. 2012; 34(12): 971-981. PMid:22066708 https://doi.org/10.3109/09638288.2011.626487

[28] Brunnström G, Sörensen S, Alsterstad K, et al. Quality of light and quality of life - the effect of lightning adaptation among people with low vision. Ophthalmic Physiol Opt. 2004; 24: 274-280. PMid:15228504 https://doi.org/10.1111/j.1475-1313.20 04.00192.x

[29] Plaza I, Martín L, Martin S, et al. Mobile applications in an aging society: Status and trends. The J Syst Software. 2011; 84: 1977-1988. https://doi.org/10.1016/j.jss.2011.05.035

[30] Ivanoff SD, Sonn U, Lundberg-Lindqvist B, et al. Disability in daily life activities and visual impairment: a population study of 85-yearold people living at home. Scand J Occup Ther. 2000; 7: 148-155. https://doi.org/10.1080/110381200300008689

[31] Elo S, Kääriäinen M, Kanste O, et al. Qualitative content analysis. A focus on trustworthiness. Sageopen. 2014; 1-10. https: //doi.org/10.1177\%2F2158244014522633 